\title{
Methods of forecasting calculations of breakthrough wave at hydrodynamic accidents waterstorage dam
}

\author{
Yermekkul Zhaparkulova ${ }^{*}$, Madina Nabiollina, and Balzhan Amanbayeva \\ Kazakh National Agrarian University
}

\begin{abstract}
The article gives the method of calculation of water storages dam at hydro technical accidents.

From natural disasters floods (flooding of water in the area and settlements) by the frequency of occurrence of the phenomenon, the area of distribution and the annual material damage ranked first. Moreover, in recent years, the world has seen an increase in the number and extent of floods and the associated social and economic losses. Both at present and in the foreseeable future, floods as a natural disaster cannot be completely prevented everywhere and everywhere, they can only be weakened, localized and with timely warning to minimize material damage. Therefore, one of the largest floods in recent years, that occurred in the West Kazakhstan region in the spring of 2011 and which took place without casualties, resulted in the allocation of more than 19 billion tenge in damage recovery from damage. Unplanned and inconsistent with general measures during floods and floods, the descent of these reservoirs can exacerbate the effects of flooding. The technical condition of the channel dams is especially dangerous. In case of possible accidents on these dams, many settlements, thousands of enterprises, millions of hectares of agricultural land can get into the affected area.

Based on the results of full-scale leveling surveys, forecasting calculations of the breakthrough of the water reservoir dams of Bartogay, Kapshagay and Kurty hydrounits have made.

Attached graphics show a dependence of water consumption at the dam breakthrough on the distance from the dam gates.
\end{abstract}

\section{Introduction}

The greatest damage caused by floods on the rivers Ertis, Ural, Tobol, Ishim, Nura, Emba, Turgai, Sary-su, etc., as well as on their numerous tributaries.

Catastrophic floods associated with wind surge on the territory of Kazakhstan observed in the Ural River delta and throughout the northeast coast of the Caspian Sea. The most dangerous are the periods from October to December and in May, when water level rises reach $2.0-2.5 \mathrm{~m}$ and seawater penetrates tens of kilometers into the territory. In recent years, the number of floods caused by anthropogenic factors has increased dramatically. On

\footnotetext{
*Corresponding author: ermekull@mail.ru
} 
the Syrdarya River, due to the transition of the Naryn cascade in the winter period to the hydropower regime, led to a forced increase in the volume of water discharge from the Shardara reservoir. Given the formation of freezing in this period in the lower reaches of the river. Syrdarya, increased discharge of water from the reservoir led to flooding of the territory. Flooding of territories threatens not only potential casualties among the population, but also violation (destruction) of infrastructure (roads, bridges, power lines, and dams), changes in natural systems (landslides, new river beds, and congestion), destruction of agricultural land and other consequences.

According to B.S. Mastryukova [2] the total direct costs associated with accidents, catastrophes and diseases caused by them, make up $4 \ldots 6 \%$ of gross domestic product. Natural disasters cause $3 \ldots 5 \%$ of premature mortality, and material damage is about $1 \%$ of IDP.

Methodical recommendations which were developed in the laboratory of bridge hydraulics and hydrology of the Department of Research and Design of Railways of Central Research Institute includes determining the costs in the dam section at its destruction, also in the sections gates of transitions located in the upper and lower dam of the waterreservoir, with considering the transformation of breakthrough waves or release in the transit watercourse [7, 8].

According to the methodic, the calculation of the breakthrough expense transformation performed for the following cases:

a) Water reservoir practically does not have a basin, feeds from groundwater is regulated in the area above the water reservoir

b) Water reservoir has its own basin; breakthrough of the dam occurs during floods, the probability of exceeding the estimated for the projected transition, with a water reservoir filled before the passage of the flood;

c) Conditions are the same as in subparagraph (b); breaks through a series of dams, located in a cascade of ponds: the first breaks the upper dam, the last one - the lower one.

\section{Methods}

With a minimum amount of initial data, the breakthrough wave modeling is performed according to simplified formulas, based on the measurements and studies (Fig.1-Fig.2) the calculation error is insignificant in comparison with resource-consuming methods.

Transverse and longitudinal profiles of the Shelek River below the Bartogay reservoir by gates (obtained on the basis of available maps and decoding of available satellite images).

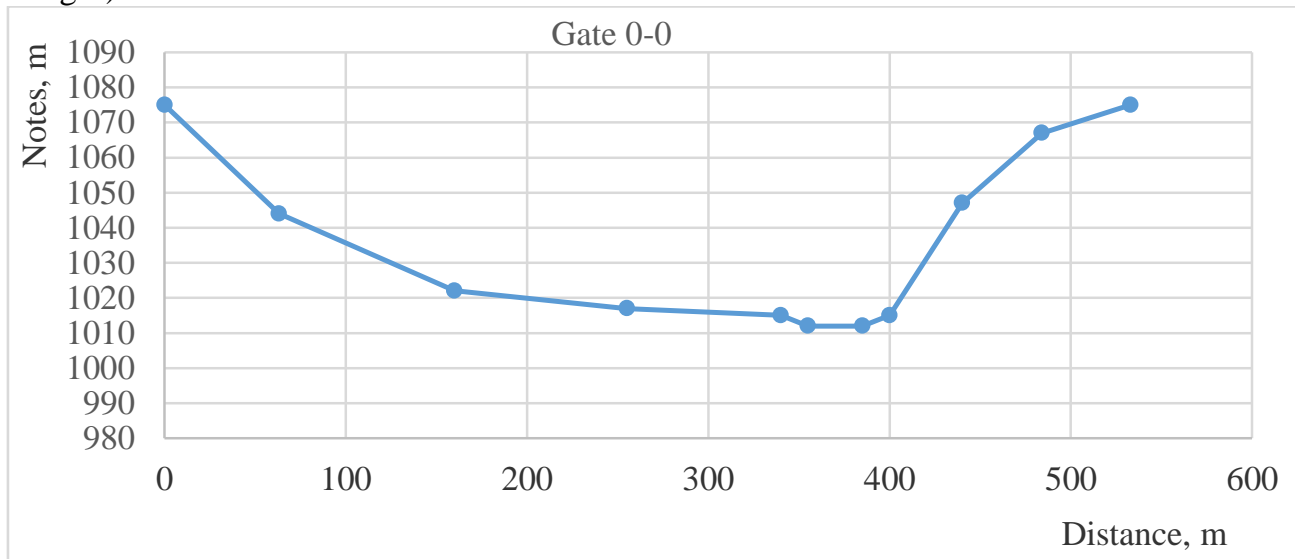

Fig. .1 Transverse profile of the gate 0-0 


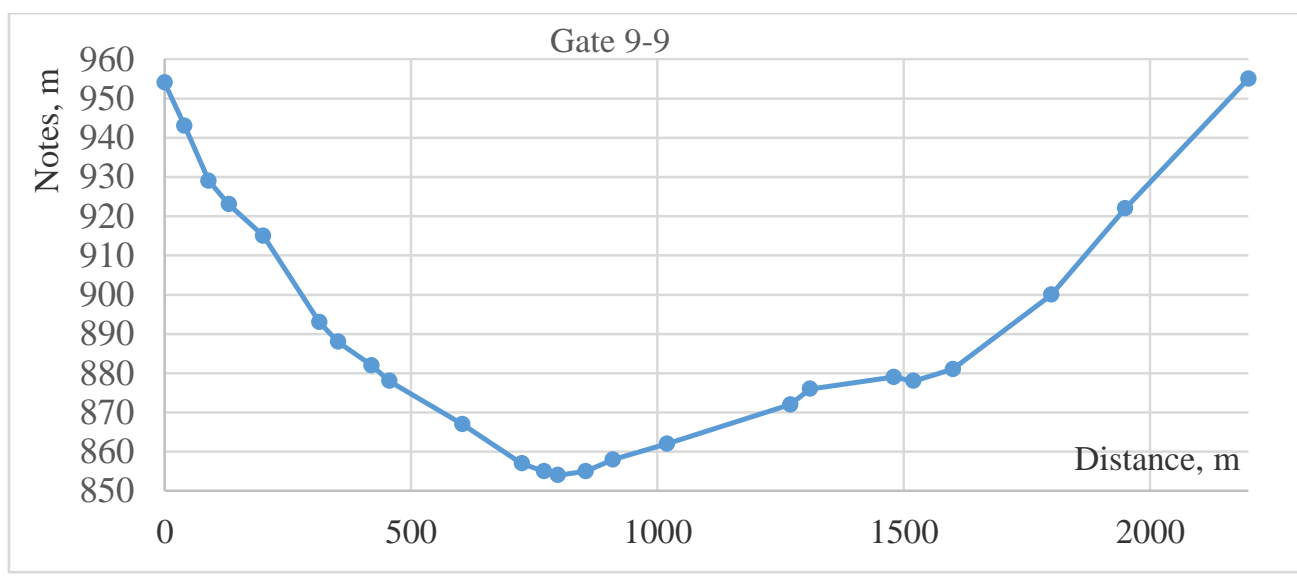

Fig. 2. Transverse profile of the gate 9-9

Expense rate in the dam gate during its breakthrough is equal to $\mathrm{Q}_{\mathrm{P}}, \mathrm{m}^{3} / \mathrm{s}$

$$
Q_{n}=B_{n} \mathrm{H}_{\mathrm{\kappa}}^{\frac{3}{2}} \mathrm{~K}_{p r}
$$

Where, $B_{n}$ is the length of the dam along the neck of water in the upper pool at the maximum filling of the water reservoir, $\mathrm{H}_{\mathrm{K}}$ - pressure (the difference in marks of water levels in the upper and lower tunnels before the breakthrough of the dam), $m ; K_{p r}$ is a coefficient that takes into account the breakthrough of the possible breakthrough width to the length of the dam $B_{n}$ and the conditions for the outflow of water during a breakout.

Table 1 gives an information about the calculated value of the coefficient $\mathrm{K}_{\mathrm{pr}}$, depending on the length of the dam $B_{n}[1,2]$.

The article uses recommendations of the State Basic Standard Requirement, rules for the operation of water reservoir hydroelectric complexes and other methodological documents on the safety of dams and hydraulic structures [3-12].

In the propagation of a breakthrough wave, the calculation of the maximum breakthrough rate of the wave in the transition range Qpm, m3 / s, is determined by the formula:

$$
\mathrm{Q}_{\text {пм }}=\frac{\mathrm{W}_{0} \mathrm{Q}_{\mathrm{n}}}{\mathrm{W}_{0}+\mathrm{Q}_{\mathrm{n}} \mathrm{L}_{\mathrm{p}} \tau}+\mathrm{Q}_{\mathrm{M}}
$$

Where, $\mathrm{Q}_{\mathrm{n}}$ is the expense in the dam section during its break, determined by formula (1), $\mathrm{m} 3 / \mathrm{s} ; \mathrm{L}_{\mathrm{p}}$ is the distance from the dam to the transition, $\mathrm{m} ; \tau$ is the coefficient characterizing the conditions of passage of the breakout wave along the transit watercourse, $\mathrm{s} / \mathrm{m} ; \mathrm{W}_{0}$ - volume of the water reservoir at the highest level of the upstream, $\mathrm{m} 3 ; \mathrm{Q}_{\mathrm{m}}$ is the possible domestic water flow rate or discharge rate from the dam weir in the transition section at the time of the breakthrough wave passage, $\mathrm{m}_{3} / \mathrm{s}$.

\section{Results}

In the case of torn fractures of the longitudinal profile of the watercourse at a length $\mathrm{Lp}$, the calculation according to formula (2) is carried out sequentially along sections with a uniform slope. To simplify the calculations is in Table. 1 the values of $\tau$ are given for different values of the slope $\tau$ of the transit watercourse.

Calculations of the maximum breakthrough wave consumption in the transition sections are summarized in tables (Table 1 of the Bartogay, Table 2-Kapshagay, Table 3-Kurty 
Reservoir) and graphs of the dependence of the flow from the distance to the dam (Fig. 3 for Bartogay, Fig. 4 for Kapshagay, Fig.5 on the Kurty reservoir).

Table 1. Bartogay water reservoir

\begin{tabular}{|c|c|c|c|c|c|}
\hline Gates & $\begin{array}{c}\text { Distance } \\
\text { between gates, } \\
\mathrm{m}\end{array}$ & $\begin{array}{c}\text { The length } \\
\text { of the } \\
\text { section } \\
\text { from the } \\
\text { beginning } \\
\text { of } \mathrm{L}_{\mathrm{p}}, \mathrm{m}\end{array}$ & $\begin{array}{c}\text { Slope of } \\
\text { the site, } \\
\% \text { o }\end{array}$ & $\begin{array}{c}\text { Coefficient } \\
\tau, \mathrm{c} / \mathrm{m}\end{array}$ & Wave consumption $\mathrm{Q}_{\text {пм }}, \mathrm{m}^{3} / \mathrm{s}$ \\
\hline $0-0$ & 0 & 0 & 1 & 1.2 & \\
\hline $1-1$ & 1010 & 1010 & 1 & 1.2 & 47109.1 \\
\hline $2-2$ & 1680 & 2690 & 2.38 & 1.0672 & 41323.5 \\
\hline $3-3$ & 1790 & 4480 & 7.82 & 0.9018 & 35378.9 \\
\hline $4-4$ & 2050 & 6530 & 6.83 & 0.9134 & 272122.6 \\
\hline $5-5$ & 2380 & 8910 & 14.3 & 0.8356 & 253.2 \\
\hline $6-6$ & 1330 & 10240 & 11.3 & 0.8596 & 23369.0 \\
\hline $7-7$ & 2000 & 12240 & 14 & 0.838 & 22284.2 \\
\hline $8-8$ & 640 & 12880 & 28.1 & 0.7495 & 20201.3 \\
\hline $9-9$ & 1220 & 14100 & 16.4 & 0.8188 & 18439.8 \\
\hline $10-10$ & 1340 & 15440 & 9.7 & 0.873 & 16998.7 \\
\hline $11-11$ & 2330 & 17770 & 10.7 & 0.8644 & 15578.7 \\
\hline $12-12$ & 2200 & 19970 & 9.09 & 0.8791 & 14295.5 \\
\hline $13-13$ & 3070 & 23040 & 10.7 & 0.8644 & 12522.6 \\
\hline $14-14$ & 5300 & 28340 & 13 & 0.846 & 10394.2 \\
\hline $15-15$ & 7900 & 36240 & 12.9 & 0.8468 & 7980.3 \\
\hline $16-16$ & 10800 & 47040 & 7.31 & 0.9069 & 5522.2 \\
\hline $17-17$ & 14600 & 61640 & 2.4 & 1.066 & \\
\hline & & & & & \\
\hline
\end{tabular}

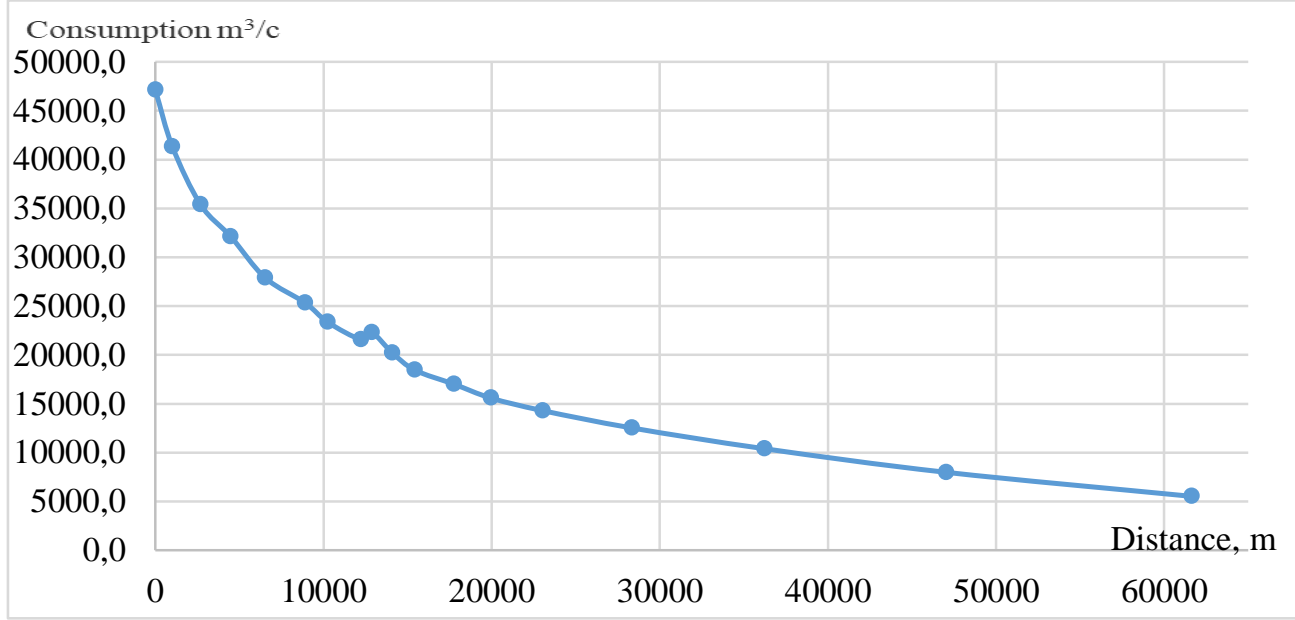

Fig. 3. The graph of the dependence of the flow from the distance to the dam - Bartogay reservoir

Table 2. Kapshagay water reservoir 


\begin{tabular}{|c|c|c|c|c|c|}
\hline Gates & $\begin{array}{c}\text { Distance } \\
\text { between gates, } \\
\mathrm{m}\end{array}$ & $\begin{array}{c}\text { The length } \\
\text { of the } \\
\text { section } \\
\text { from the } \\
\text { beginning } \\
\text { of } \mathrm{L}_{\mathrm{p}}, \mathrm{m}\end{array}$ & $\begin{array}{c}\text { Slope of } \\
\text { the site, } \\
\%\end{array}$ & $\begin{array}{c}\text { Coefficient } \\
\tau, \mathrm{c} / \mathrm{m}\end{array}$ & Wave consumption $\mathrm{Q}_{\text {пा }}, \mathrm{m}^{3} / \mathrm{s}$ \\
\hline $0-0$ & 0 & 600 & 0.833 & 1.233 & \\
\hline $1-1$ & 20200 & 20800 & 0.470 & 1.332 & 23812 \\
\hline $2-2$ & 28650 & 49450 & 0.384 & 1.370 & 23444 \\
\hline $3-3$ & 51550 & 101000 & 0.272 & 1.443 & 22920 \\
\hline $4-4$ & 49000 & 150000 & 0.367 & 1.380 & 21968 \\
\hline $5-5$ & 49000 & 199000 & 0.306 & 1.416 & 20499 \\
\hline $6-6$ & 51000 & 250000 & 0.216 & 1.487 & 19642 \\
\hline $7-7$ & 43000 & 293000 & 0.256 & 1.455 & 19159 \\
\hline $8-8$ & 57000 & 350000 & 0.175 & 1.539 & 179245 \\
\hline $9-9$ & 13000 & 363000 & 0.1538 & 1.574 & \\
\hline
\end{tabular}

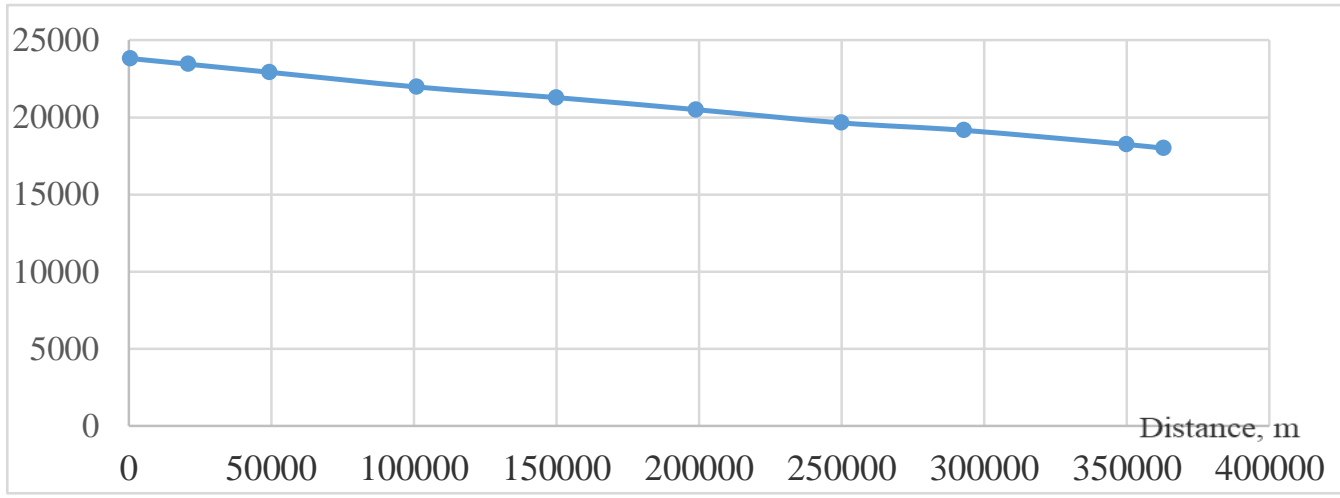

Fig. 4. The graph of the dependence of the flow from the distance to the dam- Kapshagay reservoir

Table 3. Kurty water reservoir

\begin{tabular}{|c|c|c|c|c|c|}
\hline Gates & $\begin{array}{c}\text { Distance } \\
\text { between } \\
\text { gates, } \mathrm{m}\end{array}$ & $\begin{array}{c}\text { The length of the } \\
\text { section from the } \\
\text { beginning of } \mathrm{L}_{\mathrm{p}}, \\
\mathrm{m}\end{array}$ & $\begin{array}{c}\text { Slope of } \\
\text { the site, } \\
\% \mathrm{o}\end{array}$ & $\begin{array}{c}\text { Coefficent } \\
\tau, \mathrm{c} / \mathrm{m}\end{array}$ & Wave consumption $\mathrm{Q}_{\text {пм }}, \mathrm{m}^{3} / \mathrm{s}$ \\
\hline $0-0$ & 0 & 500 & 1.500 & 1.140 & 17325 \\
\hline $1-1$ & 550 & 1050 & 2.727 & 1.046 & 16451 \\
\hline $2-2$ & 4030 & 5080 & 1.613 & 1.129 & 11635 \\
\hline $3-3$ & 5120 & 10200 & 0.781 & 1.244 & 8424 \\
\hline $4-4$ & 10700 & 20900 & 1.495 & 1.141 & 5186 \\
\hline $5-5$ & 9350 & 30250 & 1.176 & 1.179 & 4482 \\
\hline $6-6$ & 9700 & 39950 & 1.443 & 1.147 & 3732 \\
\hline $7-7$ & 10300 & 50250 & 1.262 & 1.169 & 3564 \\
\hline $8-8$ & 10230 & 60480 & 1.466 & 1.144 & \\
\hline $9-9$ & 7210 & 67690 & 1.4563 & 1.145 & \\
\hline
\end{tabular}




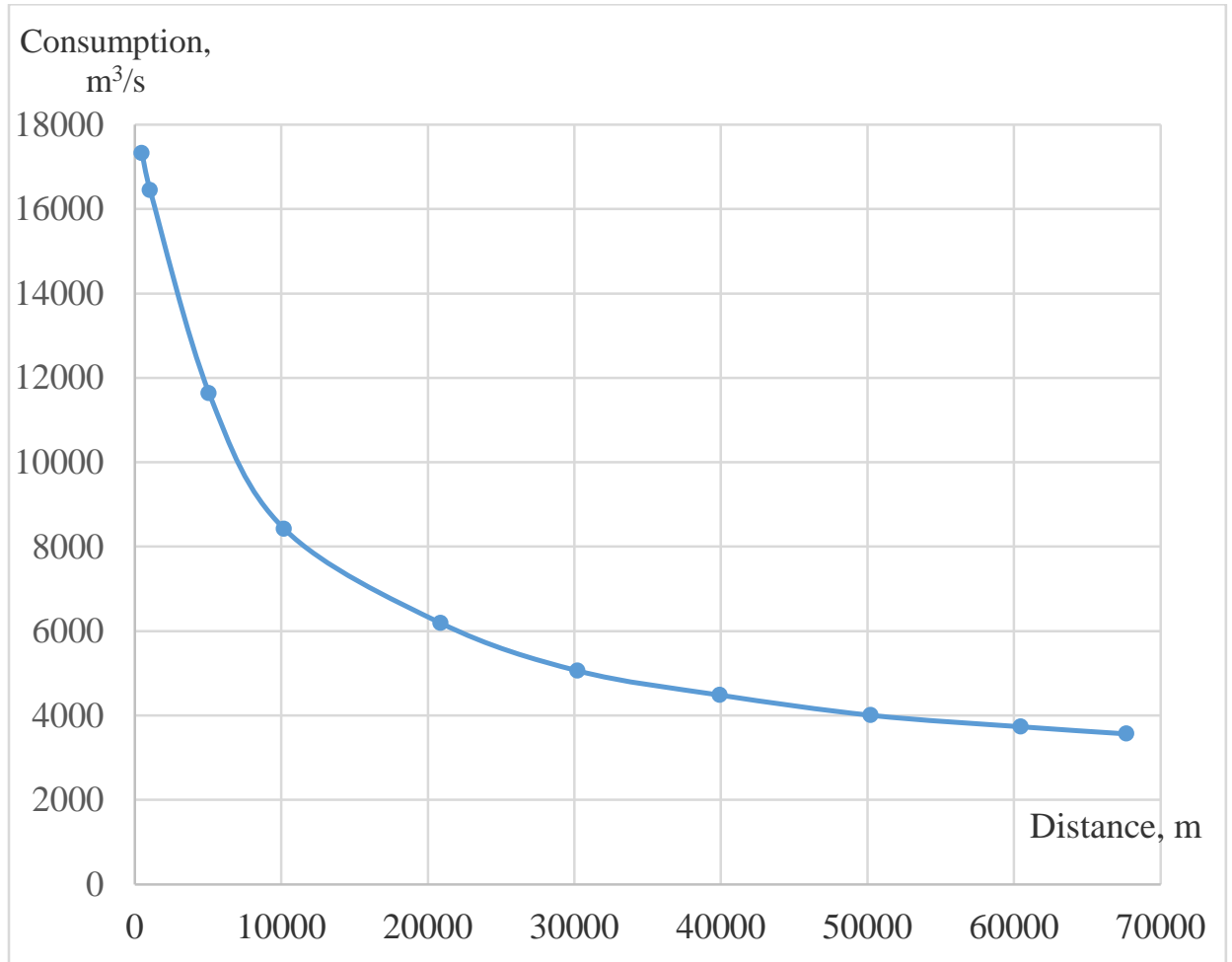

Fig. 5. The graph of the dependence of the flow from the distance to the dam - Kurty water reservoir

\section{Discussion}

1. To perform forecasting calculations of the breakthrough of water reservoir dams is in the lower pool of the waterworks, the level-theodolite survey performed at a distance of $7-8 \mathrm{~km}$ from the dam gate.

2. The rest of the crossbars removed from the satellite images using Geoformation System technology.

3. Performed hydraulic calculation breakthrough of a dam proposed in the "Methodological recommendations for determination of water consumption in the design of crossings over watercourses in the area of temporary dams"

4. Forecast calculations, determined the breakthrough wave consumption is determined as a function of remoteness from the dam section. Based on the predicted calculations, plots of the $\mathrm{Q}=\mathrm{f}(\mathrm{L})$ dependence for the Bartogay, Kapshagay and Kurty water storage reservoirs have been constructed.

5. Based on the predicted calculations, plots of the $Q=f(L)$ dependence for the Bartogay, Kapshagay and Kurty water storage water reservoirs have been constructed.

\section{Conclusions}

Hydraulic calculations will determine the parameters of the breakthrough wave, when the dam of the Kapshagay, Bartogay and Kurty reservoirs was destroyed: the height of the crest of the breakthrough wave; the breakout wave speed, as well as, the water level mark, the 
breakout wave speed and the time of the wave passage through the planned sections with the establishment of possible flooding zones in the hydrodynamic accident.

\section{References}

1. Guidelines for determining the flow of water in the design of transitions through watercourses in the zone of influence of non-capital dams. M $\therefore$ VNII transport construction, 1981.

2. Mastryukov B.S. Safety in emergency situations. - M. Academy, 2003 - 336s

3. Stepanov K.A. A technique to model a breakthrough wave to prevent possible damage caused by land flooding as a result of dam collapse. Scientific Review. Technical science. -2014. №2. Pp. 165-172.

4. Development and creation of a set of measures to ensure the safety of hydraulic structures: A methodological guide. UNECE IFAS. Almaty, 2014.

5. PP RK No. 171 dated January 30, 2012. "Rules for the operation of water facilities located directly on water bodies".

6. PP RK №29 from 12.01.2012. "Criteria for the safety of water systems and facilities."

7. PP RK No. 1449 dated December 31, 2014 "On approval of requirements for organizations certified for the right to work in the field of dam safety".

8. PP RK № 115 from 10.03.2015. "Rules defining criteria for classifying dams as declared and Rules for developing a dam safety declaration".

9. GOST R22.1.11-2202 Monitoring of the state of water-supporting hydraulic structures (dams) and forecasting the possible consequences of hydrodynamic accidents on them. General requirements.

10. Karpenchuk I.V., Striganova M.Yu. The method for determining the design parameters and graphing the movement of a breakthrough wave along a water course / I.V. Karpenchuk, // Emergencies: Prevention and Liquidation. - 2007. -№ 2 (22). - pp. 7684.

11. Karpenchuk I.V., Striganova M.Yu. The method for determining the design parameters and graphing the movement of a breakthrough wave along a water course / I.V. Karpenchuk, // Emergencies: Prevention and Liquidation. - 2007. -№ 2 (22). - pp. 7684.

12. Technical passport of hydraulic engineering facility No. 2 of the Kurtinsky reservoir. RSE "UE BV and BAK them. D. Kunaev."

13. Rules of operation of the Kurtinsky reservoir. RSE "UE BV and BAK named after Kunayev", Baiterek village, 2010.

14. Veksler AB, Ivashintsov D.A., Stefanishin D.V. Reliability, social and environmental safety of hydraulic facilities: risk assessment and decision making. St. Petersburg: OJSC VNIIG them. B.V. Vedeneyeva, 2002.

15. Stefanishin D.V. Evaluation of the regulatory safety of dams according to risk criteria // Hydraulic Engineering. 1997. № 7.

16. Zoteev V. E, Shakhov I. S. Calculation of the risk of emergency situations in small reservoirs // Ecological and water economic Bulletin. 2002. № 6.

17. Guidelines for conducting risk analysis of accidents of hydraulic structures: STF VNIIG 230.2.001-00 / VNIIGM B.Ye. Vedeneyeva, 2000.

18. Methods of operational safety assessment of hydraulic structures in long-term operation. M .: NIIES, 1997. 